\title{
(Ex-)breast cancer patients with (pre-existing) symptoms of anxiety and/or depression experience higher barriers to contact health care providers during the COVID-19 pandemic
}

\author{
Dieuwke R. Mink van der Molen ${ }^{1}$ (D) Claudia A. Bargon ${ }^{1,2} \cdot$ Marilot C. T. Batenburg $^{1} \cdot$ Roxanne Gal $^{1}$. \\ Danny A. Young-Afat ${ }^{3} \cdot$ Lilianne E. van Stam ${ }^{1} \cdot$ Iris E. van Dam ${ }^{4}$. Femke van der Leij ${ }^{4} \cdot$ Inge O O. Baas $^{5}$. \\ Miranda F. Ernst ${ }^{6} \cdot$ Wiesje Maarse $^{7} \cdot$ Nieke Vermulst $^{8} \cdot$ Ernst J. P. Schoenmaeckers $^{9} \cdot$ Thijs van Dalen $^{10}$. \\ Rhodé M. Bijlsma ${ }^{5}$. Annemiek Doeksen ${ }^{2}$. Helena M. Verkooijen ${ }^{1,11}$ on behalf of UMBRELLA study group
}

Received: 28 October 2020 / Accepted: 21 January 2021 / Published online: 18 February 2021

(c) The Author(s) 2021

\begin{abstract}
Purpose To identify factors associated with (perceived) access to health care among (ex-)breast cancer patients during the COVID-19 pandemic.

Methods Cross-sectional study within a large prospective, multicenter cohort of (ex-)breast cancer patients, i.e., UMBRELLA. All participants enrolled in the UMBRELLA cohort between October 2013 and April 2020 were sent a COVID-19-specific survey, including the Hospital Anxiety and Depression Scale (HADS) questionnaire.

Results In total, 1051 (66.0\%) participants completed the survey. During COVID-19, 284 (27.0\%) participants reported clinically relevant increased levels of anxiety and/or depression, i.e., total HADS score $\geq 12$. Participants with anxiety and/ or depression reported statistically significant higher barriers to contact their general practitioner $(47.5 \%$ vs. $25.0 \%$, resp.) and breast cancer physicians ( $26.8 \%$ vs. $11.2 \%$, resp.) compared to participants without these symptoms. In addition, a higher proportion of participants with anxiety and/or depression reported that their current treatment or (after)care was affected by COVID-19 compared to those without these symptoms (32.7\% vs. $20.5 \%$, resp.). Factors independently associated with symptoms of anxiety and/or depression during COVID-19 were pre-existent anxiety (OR 6.1, 95\% CI 4.1-9.2) or depression (OR 6.0, 95\% CI 3.5-10.2).

Conclusion During the COVID-19 pandemic, (ex-)breast cancer patients with symptoms of anxiety and/or depression experience higher barriers to contact health care providers. Also, they more often report that their health care was affected by COVID-19. Risk factors for anxiety and/or depression during COVID-19 are pre-existent symptoms of anxiety or depression. Extra attention-including mental health support—is needed for this group.
\end{abstract}

Keywords Breast cancer $\cdot$ COVID-19 $\cdot$ Depression $\cdot$ Anxiety $\cdot$ UMBRELLA $\cdot$ Patient-reported outcomes

Helena M. Verkooijen

H.M.Verkooijen@umcutrecht.nl

Dieuwke R. Mink van der Molen

d.r.minkvandermolen-2@umcutrecht.nl

1 Division of Imaging and Oncology, University Medical Center Utrecht, Heidelberglaan, Utrecht, The Netherlands

2 Department of Surgery, St. Antonius Hospital, Soestwetering, Utrecht, The Netherlands

3 Department of Plastic, Reconstructive and Hand Surgery, Amsterdam University Medical Center, Location VUmc, Amsterdam, The Netherlands

4 Department of Radiation Oncology, University Medical Center Utrecht, Cancer Center, Utrecht, The Netherlands
5 Department of Medical Oncology, University Medical Center Utrecht, Cancer Center, Utrecht, The Netherlands

6 Department of Surgery, Alexander Monro Clinics, Bilthoven, The Netherlands

7 Department of Plastic, Reconstructive and Hand Surgery, University Medical Center Utrecht, Utrecht, The Netherlands

8 Department of Surgery, Rivierenland Hospital, Tiel, The Netherlands

9 Department of Surgery, Meander Medisch Centrum, Amersfoort, The Netherlands

10 Department of Surgery, Diakonessenhuis Utrecht, Utrecht, The Netherlands

11 Utrecht University, Heidelberglaan, Utrecht, The Netherlands 


$\begin{array}{ll}\text { Abbreviations } \\ \text { CI } & \text { 95\% Confidence interval } \\ \text { COVID-19 } & \text { Coronavirus disease 2019 } \\ \text { DCIS } & \begin{array}{l}\text { Ductal carcinoma in situ } \\ \text { EORTC }\end{array} \\ & \begin{array}{l}\text { European Organization for Research and } \\ \text { Treatment of Cancer }\end{array} \\ \text { HADS } & \text { Hospital Anxiety and Depression Scale } \\ \text { IQR } & \text { Interquartile range } \\ \text { n } & \text { Number } \\ \text { NKR } & \text { Netherlands Cancer Registry } \\ \text { OR } & \text { Odds ratio } \\ \text { PRO(s) } & \text { Patient-reported outcome(s) } \\ \text { SD } & \text { Standard deviation } \\ \text { SPSS } & \text { Statistical package for social sciences } \\ \text { UMBRELLA } & \text { Utrecht cohort for Multiple BREast } \\ & \text { cancer intervention studies and Long-term } \\ & \text { evaluation } \\ \text { UMCU } & \text { University Medical Center Utrecht }\end{array}$

\section{Introduction}

The COVID-19 pandemic is having a major impact on global health. During the early months of the COVID-19 pandemic in the Netherlands, a $46 \%$ decline in general practitioner consultations, and a sharp decrease in cancer diagnoses were reported [1, 2]. Increased (perceived) thresholds to health care access may negatively affect patients' (psycho)social and physical well-being as well as their prognosis.

Symptoms of anxiety and depression among cancer patients and survivors have been reported to affect their health care behavior and health care consumption during a health threat of the magnitude of COVID-19 [3].

The aim of this study was to assess the prevalence of anxiety and depression among a large cohort of breast cancer patients and survivors during the COVID-19 pandemic. In addition, we assessed the association between the presence of symptoms of anxiety and/or depression and COVID19-specific concerns, including health care behavior and consumption.

\section{Materials and methods}

The present study was conducted within the prospective observational multicenter 'Utrecht cohort for Multiple BREast cancer intervention studies and Long-term evaLuAtion' (UMBRELLA), including patients with histologically proven invasive breast cancer or ductal carcinoma in situ (DCIS) referred from regional and tertiary referral hospitals to the University Medical Center Utrecht (UMCU) for adjuvant radiation therapy $[4,5]$. All participants completed self-reported UMBRELLA questionnaires, including the
Hospital Anxiety and Depression Scale (HADS), at regular time intervals during and after their breast cancer treatment.

All active participants, who enrolled in the UMBRELLA cohort between October 2013 and April 2020 and consented to receiving online questionnaires, were sent a survey (April 7, 2020), including the HADS and COVID-19-related questions $[6,7]$. Ethical approval was obtained from the Medical Ethics Committee of the UMCU (NL52651.041.15, METC 15/165). The UMBRELLA study is registered on clinicaltrials.gov (NCT02839863).

HADS is a 14-item questionnaire using a 4-point Likert scale. Scores $\geq 12$ on the total HADS, and scores $\geq 8$ on the 7 -item anxiety and depression subscales indicated increased risk of depression or anxiety disorder [8].

Demographic and clinical data, including age, highest educational level, type of surgery, most invasive axillary treatment, (neo-)adjuvant systemic treatment, radiotherapy, and pathological $\mathrm{T}$ and $\mathrm{N}$ stage (AJCC 7th edition), were collected in the context of UMBRELLA and provided by the Netherlands Cancer Registry (NKR) [9].

Frequencies, proportions, means with standard deviation, or medians with interquartile ranges were used to describe patient demographics, treatment characteristics and HADS scores. A Chi-square test was performed to compare differences in proportions of patients scoring above the clinically relevant HADS threshold scores before and during COVID19 [10]. Univariable and multivariable logistic regression analyses were used to evaluate to what extent relevant clinical demographic, tumor- and treatment characteristics affected clinically relevant symptoms of anxiety and/ or depression during COVID-19. Two-sided $p$ values $<0.05$ were considered statistically significant. Statistical analyses were performed with IBM Statistical Package for Social Sciences (SPSS) software, version 25 (IBM Corp, Armonk, NY).

\section{Results}

Of the 3239 participants enrolled in the UMBRELLA cohort between October 2013 and April 2020, 1595 participants met the inclusion criteria. Of those, $1051(66.0 \%)$ participants completed the COVID-19-specific questionnaire, of which $4.9 \%(n=51)$ were under active treatment for their breast cancer.

\section{Prevalence and risk factors for anxiety and/ or depression during COVID-19}

Overall, 284 (27.0\%) participants experienced clinically relevant symptoms of anxiety and/or depression during COVID-19 (Table 1). Of all participants who experienced symptoms of anxiety and/or depression during COVID-19, 
Table 1 Baseline characteristics of participants with or without a clinically relevant increase in total HADS score $(\geq 12)$, i.e., symptoms of anxiety and/or depression, as measured by the HADS questionnaire during the COVID-19 pandemic $(n=1051)$

\begin{tabular}{|c|c|c|c|c|c|}
\hline $\begin{array}{l} \\
\text { Patient characteristics }\end{array}$ & \multicolumn{2}{|c|}{$\begin{array}{l}\text { Participants with } \\
\text { a total HADS } \\
\text { score }<12^{\mathrm{a}} \\
(n=767)\end{array}$} & \multicolumn{2}{|c|}{$\begin{array}{l}\text { Participants with } \\
\text { a total HADS } \\
\text { score } \geq 12^{\mathrm{a}} \\
(n=284)\end{array}$} & $p$ value \\
\hline Age in years at inclusion, mean (SD) & 57 & 9.6 & 55 & 10.1 & 0.003 \\
\hline Sex, No. $(\%)$ & & & & & 0.135 \\
\hline Female & 761 & 99.2 & 284 & 100.0 & \\
\hline Male & 6 & 0.8 & 0 & 0.0 & \\
\hline Highest educational level & & & & & 0.185 \\
\hline Primary or (post-)secondary school & 326 & 42.5 & 133 & 46.8 & \\
\hline College or university & 434 & 56.6 & 147 & 51.8 & \\
\hline Unknown & 7 & 0.9 & 4 & 1.4 & \\
\hline Time since diagnosis (months), median (IQR) & 24 & $6-42$ & 24 & $6-42$ & 0.859 \\
\hline Unknown, No. (\%) & 6 & 0.8 & 3 & 1.1 & \\
\hline \multicolumn{6}{|l|}{ Tumor characteristics } \\
\hline Pathological T stadium & & & & & 0.698 \\
\hline In situ (IS), 0, I or II & 698 & 91.0 & 256 & 90.1 & \\
\hline III or IV & 15 & 2.0 & 8 & 2.8 & \\
\hline $\mathrm{X}$ or unknown & 54 & 7.0 & 20 & 7.0 & \\
\hline Pathological N stadium & & & & & 0.005 \\
\hline 0 & 461 & 60.1 & 145 & 51.1 & \\
\hline I, II or III & 198 & 25.8 & 102 & 35.9 & \\
\hline $\mathrm{X}$ or unknown & 108 & 14.1 & 37 & 13.0 & \\
\hline \multicolumn{6}{|l|}{ Treatment characteristics } \\
\hline Type of breast surgery & & & & & 0.112 \\
\hline Breast conserving therapy & 596 & 77.7 & 217 & 76.4 & \\
\hline Mastectomy & 70 & 9.1 & 24 & 8.5 & \\
\hline Mastectomy with direct breast reconstruction & 65 & 8.5 & 28 & 9.9 & \\
\hline No breast surgery & 0 & 0.0 & 2 & 0.7 & \\
\hline Unknown & 36 & 4.7 & 13 & 4.6 & \\
\hline Most invasive axillary treatment & & & & & 0.509 \\
\hline Sentinel node procedure & 572 & 74.6 & 212 & 74.6 & \\
\hline Axillary lymph node dissection ${ }^{\mathrm{b}}$ & 56 & 7.3 & 26 & 9.2 & \\
\hline Unknown or not performed & 139 & 18.1 & 46 & 16.2 & \\
\hline Systemic therapy ${ }^{\mathrm{c}}$ & & & & & 0.008 \\
\hline No systemic therapy & 168 & 21.9 & 38 & 13.4 & \\
\hline Chemotherapy $^{\mathrm{d}}$ & 261 & 34.0 & 117 & 41.2 & \\
\hline Endocrine therapy or immunotherapy & 102 & 13.3 & 45 & 15.8 & \\
\hline Unknown & 236 & 30.8 & 84 & 29.6 & \\
\hline Radiation therapy & & & & & 0.003 \\
\hline Local & 515 & 67.1 & 163 & 57.4 & \\
\hline Locoregional $^{\mathrm{e}}$ & 158 & 20.6 & 86 & 30.3 & \\
\hline No radiation therapy or type unknown & 94 & 12.3 & 35 & 12.3 & \\
\hline Currently receiving active breast cancer treatment ${ }^{\mathrm{f}}$ & & & & & 0.779 \\
\hline Yes & 37 & 4.8 & 14 & 4.9 & \\
\hline No & 723 & 94.3 & 266 & 93.7 & \\
\hline Other & 7 & 0.9 & 4 & 1.4 & \\
\hline \multicolumn{6}{|l|}{ Hospital Anxiety and Depression Scale } \\
\hline Total HADS score before COVID-19, & & & & & $<0.001$ \\
\hline Above threshold & 64 & 9.3 & 156 & 62.7 & \\
\hline Below threshold & 627 & 90.7 & 93 & 37.3 & \\
\hline
\end{tabular}


Table 1 (continued)

\begin{tabular}{|c|c|c|c|c|c|}
\hline & \multicolumn{2}{|c|}{$\begin{array}{l}\text { Participants with } \\
\text { a total HADS } \\
\text { score }<12^{\mathrm{a}} \\
(n=767)\end{array}$} & \multicolumn{2}{|c|}{$\begin{array}{l}\text { Participants with } \\
\text { a total HADS } \\
\text { score } \geq 12^{\mathrm{a}} \\
(n=284)\end{array}$} & \multirow{2}{*}{$\begin{array}{l}p \text { value } \\
<0.001\end{array}$} \\
\hline & & & & & \\
\hline Above threshold & 57 & 8.2 & 124 & 49.8 & \\
\hline Below threshold & 634 & 91.8 & 125 & 50.2 & \\
\hline HADS depression score before COVID-19 $9^{\mathrm{a}, \mathrm{g}}$ & & & & & $<0.001$ \\
\hline Above threshold & 26 & 3.8 & 89 & 35.7 & \\
\hline Below threshold & 665 & 96.2 & 160 & 64.3 & \\
\hline
\end{tabular}

As a result of rounding, percentages may not total to $100 \%$

$I Q R$ interquartile range, $n$ number, $S D$ standard deviation, HADS Hospital Anxiety and Depression Score

${ }^{a}$ A clinically relevant total HADS score $\geq 12$ (above threshold) indicates a probable depression and/or anxiety disorder

${ }^{\mathrm{b}}$ Axillary lymph node dissection (in combination with sentinel node procedure)

${ }^{\text {c}}$ Pre- and/or postoperative therapy

${ }^{\mathrm{d}}$ Chemotherapy (in combination with other systemic therapy, i.e., immunotherapy, endocrine therapy)

${ }^{\mathrm{e}}$ Including supraclavicular and/or axillary lymph nodes

${ }^{\mathrm{f}}$ Active treatment includes chemotherapy and/or radiation therapy

${ }^{g}$ Only patients with known HADS scores as obtained in UMBRELLA within 2 years before the first official COVID-19 diagnosis in the Netherlands (February 27, 2020) were included for comparative analyses with HADS scores from the COVID-19-specific questionnaire $(n=940)$

$62.7 \%(n=156)$ already experienced these symptoms preCOVID-19. A total of $18.2 \%(n=191)$ of all participants reported symptoms of anxiety and $16.0 \%(n=168)$ symptoms of depression during the pandemic. The proportion of participants experiencing symptoms of anxiety and/or depression was slightly, but significantly lower before the pandemic $(23.4 \%, n=220)$.

Lower age, higher pathological $\mathrm{N}$ stage, receipt of systemic therapy or radiotherapy and pre-existent symptoms of anxiety or depression were significantly associated with anxiety and/or depression during COVID-19 (Table 1). In multivariable analysis, only pre-existent symptoms of anxiety or depression were independently and significantly associated with symptoms of anxiety and/or depression during COVID-19 (OR 6.1, 95\% CI 4.1-9.2 and OR 6.0, 95\% CI 3.5-10.2, resp., Table 2).

\section{COVID-19-specific concerns and health care consumption}

Significantly more participants with anxiety and/or depression experienced higher barriers to contact their general practitioner ( $47.5 \%$ vs. $25.0 \%$, resp.) and breast cancer physicians $(26.8 \%$ vs. $11.2 \%$, resp.) compared to patients without these symptoms (Table 3 ). In addition, a higher proportion of participants with anxiety and/or depression reported that their current treatment or (after)care was affected by COVID-19 compared to those without these symptoms (32.7\% vs. $20.5 \%$, resp.).
Table 2 Multivariable logistic regression analysis of risk factors for clinically relevant increase in symptoms of anxiety and/or depression, i.e., total HADS score above threshold $(\geq 12)$, during the COVID-19 pandemic $(n=940)$

\begin{tabular}{|c|c|c|}
\hline Variables & OR & $95 \% \mathrm{CI}$ \\
\hline Age & 0.99 & $0.97-1.01$ \\
\hline \multicolumn{3}{|l|}{ Pathological N stadium } \\
\hline 0 & Ref. & \\
\hline I, II or III & 1.12 & $0.67-1.85$ \\
\hline $\mathrm{X}$ or unknown & 1.36 & $0.75-2.45$ \\
\hline \multicolumn{3}{|l|}{ Systemic therapy ${ }^{\mathrm{a}}$} \\
\hline No systemic therapy & Ref. & \\
\hline Chemotherapy $^{\mathrm{b}}$ & 1.48 & $0.85-2.55$ \\
\hline Endocrine therapy or immunotherapy & 1.55 & $0.83-2.88$ \\
\hline Unknown & 1.41 & $0.81-2.44$ \\
\hline \multicolumn{3}{|l|}{ Radiation therapy } \\
\hline Local & Ref. & \\
\hline Locoregional $^{c}$ & 1.49 & $0.89-2.51$ \\
\hline No radiation therapy or type unknown & 0.83 & $0.45-1.55$ \\
\hline \multicolumn{3}{|l|}{ HADS anxiety score before COVID-19 ${ }^{a}$} \\
\hline Below threshold & Ref. & \\
\hline Above threshold & 6.12 & $4.05-9.24$ \\
\hline \multicolumn{3}{|l|}{ HADS depression score before COVID-19 } \\
\hline Below threshold & Ref. & \\
\hline Above threshold & 5.95 & $3.48-10.18$ \\
\hline
\end{tabular}

${ }^{\text {a } P r e-~ a n d / o r ~ p o s t o p e r a t i v e ~ t h e r a p y ~}$

${ }^{\mathrm{b}}$ Chemotherapy (in combination with other systemic therapy, i.e., immunotherapy, endocrine therapy)

${ }^{\mathrm{c}}$ Including supraclavicular and/or axillary lymph nodes 
Table 3 Patient-reported outcomes of COVID-19-specific concerns in the early months of the COVID-19 pandemic in the Netherlands $(n=1051)$

\begin{tabular}{|c|c|c|c|c|c|}
\hline & \multicolumn{2}{|c|}{$\begin{array}{l}\text { Partici- } \\
\text { pants with } \\
\text { a total } \\
\text { HADS } \\
\text { score }<12 \\
\text { during } \\
\text { COVID- } \\
19^{\text {a }}\end{array}$} & \multicolumn{2}{|c|}{$\begin{array}{l}\text { Partici- } \\
\text { pants with } \\
\text { a total } \\
\text { HADS } \\
\text { score } \geq 12 \\
\text { during } \\
\text { COVID- } \\
19^{a}\end{array}$} & \multirow[t]{2}{*}{$p$ value } \\
\hline & No. & $\%$ & No. & $\%$ & \\
\hline Are/were you infected by the COVID-19? & & & & & 0.368 \\
\hline Yes, confirmed by nasopharyngeal swab & 1 & 0.1 & 0 & 0.0 & \\
\hline Possibly, I have or had fever & 66 & 8.6 & 34 & 12.0 & \\
\hline No, I was tested negative & 7 & 0.9 & 2 & 0.7 & \\
\hline No, I had/have no symptoms and I was not tested & 693 & 90.4 & 248 & 87.3 & \\
\hline Is the current COVID-19 measure affecting your current treatment or aftercare? & & & & & $<0.001$ \\
\hline Yes & 184 & 24.0 & 102 & 35.9 & \\
\hline No & 583 & 76.0 & 182 & 64.1 & \\
\hline Do you expect that the current COVID-19 measures will affect your treatment or aftercare in the future? & & & & & $<0.001$ \\
\hline Yes & 157 & 20.5 & 93 & 32.7 & \\
\hline No & 610 & 79.5 & 191 & 67.3 & \\
\hline Did the threshold to contact your general practitioner change, because of the COVID-19 situation? & & & & & $<0.001$ \\
\hline Yes, I contact my general practitioner more easily & 13 & 1.7 & 6 & 2.1 & \\
\hline Yes, I contact my general practitioner less easily & 192 & 25.0 & 135 & 47.5 & \\
\hline No & 562 & 73.3 & 143 & 50.4 & \\
\hline $\begin{array}{l}\text { Did the threshold to contact the physicians treating your breast cancer change, because of the COVID-19 situ- } \\
\text { ation? }\end{array}$ & & & & & $<0.001$ \\
\hline Yes, I contact my breast cancer physicians more easily & 7 & 0.9 & 1 & 0.4 & \\
\hline Yes, I contact my breast cancer physicians less easily & 86 & 11.2 & 76 & 26.8 & \\
\hline No & 674 & 87.9 & 207 & 72.9 & \\
\hline
\end{tabular}

${ }^{\mathrm{a}}$ A clinically relevant total HADS score $\geq 12$ (above threshold) indicates a probable depression and/or anxiety disorder

\section{Discussion}

During the COVID-19 pandemic, $27.0 \%$ of the (ex-)breast cancer patients reported clinically relevant symptoms of anxiety and/or depression. (Ex-)breast cancer patients with anxiety and/or depression reported to experience higher thresholds to contact their health care providers. Factors independently associated with anxiety and/or depression during COVID-19 were pre-existent symptoms of anxiety or depression.

In the early months of the COVID-19 pandemic, a sharp decrease in cancer diagnoses and a $46 \%$ decline in general practitioner consultations were observed in the Netherlands $[1,2]$. In this study, participants with anxiety and/or depression reported higher barriers to contact their health care providers during COVID-19 compared to those without these symptoms. The COVID-19 pandemic might have increased the perceived burden on patients with symptoms of anxiety and/or depression. High levels of anxiety and perceived threat have been shown to be related to increased avoidance behavior [11]. Anxiety for a COVID-19 infection, a higher level of moral concerns about wasting the physicians' time for non-COVID-19-related symptoms, and assumptions about scarcity in the capacity of health care services for non-COVID-19-related care might also explain these barriers in seeking health care among patients with symptoms of anxiety and/or depression [1]. These results suggest that, in case of subsequent waves or a future pandemic, (ex-)breast cancer patients experiencing anxiety and/or depression are especially at risk for reduced health care consumption and may need extra encouragement to contact their health care providers, when necessary.

The proportion of participants experiencing anxiety and/ or depression increased only slightly during COVID-19 (27.0\%), when compared to pre-COVID-19 (23.4\%). However, there was a considerable shift: quite some patients with pre-existing symptoms of anxiety and/or depression no longer experienced clinically relevant levels of anxiety 
and/or depression during COVID-19 and vice versa. The participants' perception of the COVID-19 pandemic and different coping mechanisms might play a role in this shift [11]. Higher tolerance for uncertainty is related to better coping strategies and lower threat appraisal. For example, patients who tolerated uncertainty better, experienced lower levels of anxiety during the H1N1 pandemic in 2009 and showed higher levels of problem-focused coping [11]. However, further studies are needed to better understand these coping mechanisms in the context of a major health threat, and their effect on health care consumption.

Our findings that $18.2 \%$ of all participants reported symptoms of anxiety and $16.0 \%$ symptoms of depression, are in line with outcomes previously reported among UMBRELLA participants with early invasive breast cancer or DCIS prior to COVID-19 at 24 months after diagnosis (anxiety $12.5-17.1 \%$, depression $6.0-16.1 \%$ ) [12]. Moreover, the observed proportion of (ex-)breast cancer patients with anxiety and/or depression during COVID-19 seemed even lower when compared to the general population. A recent meta-analysis assessing anxiety and depression among a general population in Europe during COVID-19 observed that $32.4 \%(n=8.341)$ experienced symptoms of anxiety and $23.8 \%(n=8.341)$ symptoms of depression [13].

Although previous research showed that mental health can be impaired in the context of a major health threat, there are still insufficient clinical (screening) tools that can help identify those at risk [14]. Pre-existent anxiety and/ or depression was reported by $62.7 \%(n=156)$ of the participants with anxiety and/or depression during COVID-19. Similarly, a recent global study among non-cancer patients with pre-existent anxiety or depression $(n=2.734)$ reported worsening of psychological well-being in at least $50.0 \%$ during COVID-19 [15].

With the aim of providing adequate (mental) health support in the context of a health threat of this magnitude, surveillance and clear documentation of symptoms of anxiety and/or depression prior to and during major health threats seem a valuable tool to identify those at risk for reduced health care consumption. Especially in times of lockdown and social distancing, integration of e-mental health applications and digital psychological interventions is important to improve supportive care for those at risk. Last, raising public awareness about the importance of encouraging these particularly vulnerable individuals to contact their health care professionals, when necessary, is warranted.

\section{Conclusion}

Reduced health care consumption, and increased thresholds to contact health care professionals following the COVID-19 pandemic are reasons for concern. We found that (ex-)breast cancer patients with symptoms of anxiety and/or depression experienced higher barriers in seeking health care. Patients with pre-existent symptoms of anxiety or depression were particularly at risk for (worsening of) anxiety and/or depression during the pandemic.

Author contributions The corresponding author (HMV) confirms that she had full access to all the data in the study and had final responsibility for the decision to submit for publication. All listed authors did not receive any writing assistance and have approved the manuscript before submission. Each author has contributed significantly to, and is willing to take public responsibility for, the following aspects of the study. Design DRMM, CAB, MCTB, RG, LES, WM, NV, IED, FL, EJPS, MFE, IOB, TD, RB, DAYA, AD, HMV. Data acquisition DRMM, CAB, MCTB, LES, AD, HMV. Analyses DRMM, CAB, RG, MCTB, DAYA, HMV. Interpretation DRMM, CAB, RG, MCTB, DAYA, HMV. Drafting DRMM, CAB. Critical revision DRMM, CAB, MCTB, RG, LES, WM, NV, IED, F. van der Leij, EJPS, MFE, IOB, TD, RB, DAYA, AD, HMV.

Funding The authors received no financial support for the research (including study design; data collection, analysis, interpretation of data; and writing of the report), authorship, and/ or (the decision to submit the article for) publication.

Data availability Raw data were generated at the University Medical Center Utrecht. Derived data supporting the findings of this study are available from the corresponding author Prof Dr HM Verkooijen upon reasonable request.

\section{Compliance with ethical standards}

Conflict of interest The authors have no conflicts of interest to disclose.

Ethical approval This study was in accordance with the ethical standards of the institutional and/or national research committee and with the 1964 Helsinki declaration and its later amendments or comparable ethical standards.

Consent to participate Informed consent from all individual participants was obtained within the UMBRELLA cohort.

Consent to publish Informed consent from all individual participants was obtained within the UMBRELLA cohort.

Open Access This article is licensed under a Creative Commons Attribution 4.0 International License, which permits use, sharing, adaptation, distribution and reproduction in any medium or format, as long as you give appropriate credit to the original author(s) and the source, provide a link to the Creative Commons licence, and indicate if changes were made. The images or other third party material in this article are included in the article's Creative Commons licence, unless indicated otherwise in a credit line to the material. If material is not included in the article's Creative Commons licence and your intended use is not permitted by statutory regulation or exceeds the permitted use, you will need to obtain permission directly from the copyright holder. To view a copy of this licence, visit http://creativecommons.org/licenses/by/4.0/. 


\section{References}

1. Dinmohamed AG, Visser O, Verhoeven RHA et al (2020) Fewer cancer diagnoses during the COVID-19 epidemic in the Netherlands. Lancet Oncol. https://doi.org/10.1016/S1470 $-2045(20) 30265-5$

2. Batenburg R, Vis E, Keuper J, Bosmans MLC (2020) Drukte en uitgestelde zorgvraag door de COVID-19-pandemie: regionale verschillen. Gevolgen corona in de huisartsenpraktijk. Nivel, Utrecht. https://www.nivel.nl/sites/default/files/bestanden/10037 70_2.pdf. Accessed 29 June 2020

3. Wang Y, Duan Z, Ma Z et al (2020) Epidemiology of mental health problems among patients with cancer during COVID-19 pandemic. Transl Psychiatry 10:263. https://doi.org/10.1038/ s41398-020-00950-y

4. Young-Afat DA, van Gils CH, van den Bongard HJGD et al (2017) The Utrecht cohort for Multiple BREast cancer intervention studies and Long-term evaLuAtion (UMBRELLA): objectives, design, and baseline results. Breast Cancer Res Treat 164:445-450. https ://doi.org/10.1007/s10549-017-4242-4

5. Gal R, Monninkhof EM, van Gils CH et al (2019) The Trials within cohorts design faced methodological advantages and disadvantages in the exercise oncology setting. J Clin Epidemiol. https://doi.org/10.1016/j.jclinepi.2019.05.017

6. Aaronson NK, Ahmedzai S, Bergman B et al (1993) The European organization for research and treatment of cancer QLQ-C30: a quality-of-life instrument for use in international clinical trials in oncology. J Natl Cancer Inst. https://doi.org/10.1093/jnci/85.5.365

7. Spinhoven P, Ormel J, Sloekers PPA et al (1997) A validation study of the hospital anxiety and depression scale (HADS) in different groups of Dutch subjects. Psychol Med. https://doi. org/10.1017/S0033291796004382

8. Zigmond AS, Snaith RP (1983) The hospital anxiety and depression scale. Acta Psychiatr Scand. https://doi. org/10.1111/j.1600-0447.1983.tb09716.x
9. Netherlands Cancer Registry (2020) http://www.cijfersoverkank er.nl. Accessed 10 Jun 2020

10. Giesinger JM, Loth FLC, Aaronson NK et al (2020) Thresholds for clinical importance were established to improve interpretation of the EORTC QLQ-C30 in clinical practice and research. J Clin Epidemiol. https://doi.org/10.1016/j.jclinepi.2019.10.003

11. Taha S, Matheson K, Cronin T et al (2014) Intolerance of uncertainty, appraisals, coping, and anxiety: the case of the 2009 H1N1 pandemic. Br J Health Psychol. https://doi.org/10.1111/ bjhp. 12058

12. Gregorowitsch ML, van den Bongard HJGD, Young-Afat DA et al (2018) Severe depression more common in patients with ductal carcinoma in situ than early-stage invasive breast cancer patients. Breast Cancer Res Treat 167:205-213. https://doi.org/10.1007/ s10549-017-4495-y

13. Salari N, Hosseinian-Far A, Jalali R et al (2020) Prevalence of stress, anxiety, depression among the general population during the COVID-19 pandemic: a systematic review and meta-analysis. Global Health. https://doi.org/10.1186/s12992-020-00589-w

14. Brooks SK, Webster RK, Smith LE et al (2020) The psychological impact of quarantine and how to reduce it: rapid review of the evidence. Lancet. https://doi.org/10.1016/S0140-6736(20)30460 $-8$

15. Gobbi S, Plomecka MB, Ashraf Z et al (2020) Worsening of preexisting psychiatric conditions during the COVID-19 pandemic. medRxiv. https://doi.org/10.1101/2020.05.28.20116178

Publisher's Note Springer Nature remains neutral with regard to jurisdictional claims in published maps and institutional affiliations. 